\title{
Reconstrucción de extremidades inferiores con colgajo sural diferido.
}

Sural flap in the coverage of lower extremity wounds using differed transposition technique.

\author{
HUIMAN LAZO Victor*, BARDALES LASTEROS Alberto**, ARCE CHIRINOS Dante***, IRIARTE BLAS \\ Jesús****.
}

\begin{abstract}
SUMMARY
Objective: To evaluate viability of sural flap in the coverage of lower extremity wounds that expose their vascular pedicle zone, using differed transposition technique. Material and Methods: We included 8 patients with reconstructive surgery of lower extremity wounds, of plastic surgery division of the Hospital Nacional Cayetano Heredia, from June 2001 to May 2003. We used differed transposition technique with sural flap in the coverage of wounds. Results: Social flaps were viable in all of cases, in time of transposition. The most frequent complication was partial necrosis. Conclusion: Differed transposition technique is adequate to support viability of sural flaps in these cases. (Rev Med Hered 2004;15:155-158).
\end{abstract}

KEY WORDS: Sural flap, differed transposition technique, extremity wound.

\section{RESUMEN}

Objetivo: Evaluar la viabilidad del colgajo sural, en lesiones de extremidades inferiores que comprometen la zona de su pedículo vascular utilizando la técnica quirúrgica de transposición diferida o de retardo. Materiales y Métodos: Se estudiaron 08 pacientes sometidos a cirugía reconstructiva con colgajo sural diferido por lesiones en tercio distal de extremidades inferiores que comprometían la zona de su pedículo vascular, desde junio 2001 a mayo 2003, en el Servicio de Cirugía Plástica del Hospital Nacional Cayetano Heredia. Resultados: El 100\% de colgajos estuvo viable al momento de realizar la transposición. Las complicaciones encontradas fueron menores, siendo la más frecuente la necrosis parcial. Conclusiones: La técnica diferida utilizada en el colgajo sural, cuando la lesión compromete la zona de su pedículo vascular, es adecuada para mantener la viabilidad del colgajo.(Rev Med Hered 2004;15:155158).

PALABRAS CLAVE: Colgajo sural, diferido.

Residente 3er año de Cirugía Plástica y Reconstructiva Universidad Peruana Cayetano Heredia - Hospital Nacional Cayetano Heredia.

** Cirujano Plástico. Jefe del Servicio de Cirugía Plástica y Reconstructiva del Hospital Nacional Cayetano Heredia.

*** Médico Cirujano. Rotante Cirugía Plástica y Reconstructiva del Hospital Nacional Cayetano Heredia

*** Cirujano Plástico. Ex-residente Cirugía Plástica y Reconstructiva Hospital Nacional Cayetano Heredia. 


\section{INTRODUCCIÓN}

La reconstrucción de defectos de tejidos blandos en tercio inferior de pierna, talón, maléolos y pie, son frecuentes en la practica habitual y representan un reto para el cirujano plástico $(1,2,3)$.

Desde que Masquelet describió el colgajo sural en 1992, se ha difundido su uso a través de los años para la reconstrucción de extremidades inferiores, con resultados favorables y mínimas complicaciones, constituyéndose en una alternativa de primera elección para cubrir defectos agudos y crónicos $(3,4)$.

Son muchos los estudios que describen el éxito del uso del colgajo sural por ser técnicamente fácil de realizar, versátil, con escaso compromiso funcional en la zona donante y con complicaciones mínimas. Sin embargo, advierten tener cuidado en la utilización del colgajo cuando la lesión o su secuela comprometen la zona de su pedículo neurovascular $(2,3)$.

La técnica del retardo o de diferir el transporte del colgajo es útil en condiciones que desfavorecen el aporte vascular, por lesiones que comprometen el origen o el trayecto del mismo, mejorando la viabilidad y asegurando su sobrevida. El periodo de retardo puede ser de 3 a 4 semanas (3).

El presente estudio se realiza en pacientes con lesiones de extremidades inferiores que involucran tercio inferior de pierna, talón y maléolos. El objetivo del estudio fue evaluar la viabilidad del colgajo sural empleado en estos pacientes, utilizando la técnica quirúrgica de transposición diferida a de retardo.

\section{MATERIALES Y MÉTODOS}

Estudio prospectivo y descriptivo.

Se estudiaron 08 pacientes sometidos a cirugía reconstructiva con colgajo sural diferido por lesiones en tercio distal de extremidades inferiores que comprometen la zona de su pedículo vascular en el período de junio del 2001 a mayo del 2003, en el Servicio de Cirugía Plástica y Reconstructiva del Hospital Nacional Cayetano Heredia.

\section{Procedimiento:}

Se planificó la cirugía de reconstrucción con colgajo sural diferido de las lesiones descritas anteriormente. El procedimiento quirúrgico fue realizado en dos tiempos: En el primer tiempo, se diseñó el colgajo sural fasciocutáneo, considerando la isla de piel correspondiente para cubrir el defecto. Se disecó el colgajo teniendo en cuenta la inclusión del nervio sural y de la vena safena menor, hasta la región del pedículo inferior a $05 \mathrm{~cm}$ por encima del maléolo externo (Figura $\mathrm{N}^{\circ} 1$ ).

En la disección se repara en forma distal y proximal la arteria y vena sural en el borde superior del colgajo, con suturas que quedan sin anudarlos, y los cabos largos fijándolos a la piel y ejerciendo un cierto grado de tensión a fin de ocluir los vasos. El colgajo disecado y levantado es colocado nuevamente sobre su lecho de origen suturando la piel con Nylon 5/0 (Figura ${ }^{\circ} 2$ ).

En el postoperatorio inmediato se revisó la viabilidad del colgajo hasta las 24 horas y luego se ligaron los vasos reparados. Una vez comprobada la viabilidad del colgajo y descartando todo indicio de sufrimiento vascular, se procedió a darle de alta al paciente para su control en forma ambulatoria.

El segundo tiempo quirúrgico se realizó después de 3 a 4 semanas y consistió en disecar y transponer el colgajo hacia el lecho receptor cubriendo el defecto. La zona donante se cubrió con injerto de piel parcial. En nuestro estudio la transposición se realizó sin tunelización del colgajo (Figura $\mathrm{N}^{\circ} 3$ ). En el postoperatorio inmediato se monitorizó la viabilidad del colgajo. Una vez comprobado que los injertos de piel en la zona donante se encontraban en buen estado se

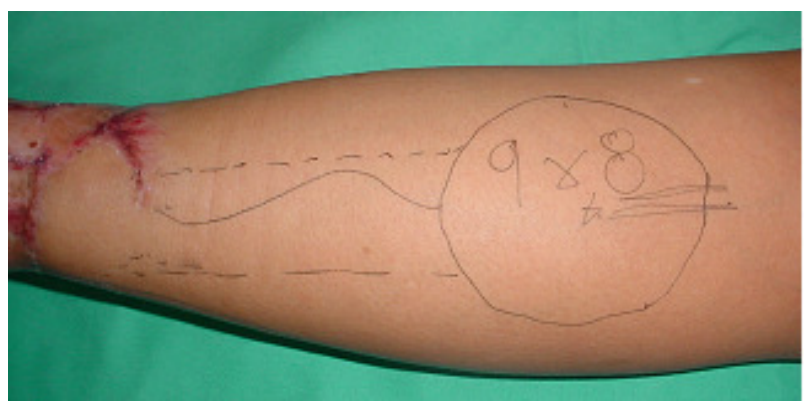

Figura $\mathbf{N}^{\mathbf{0}}$ 1. Diseño de colgajo.

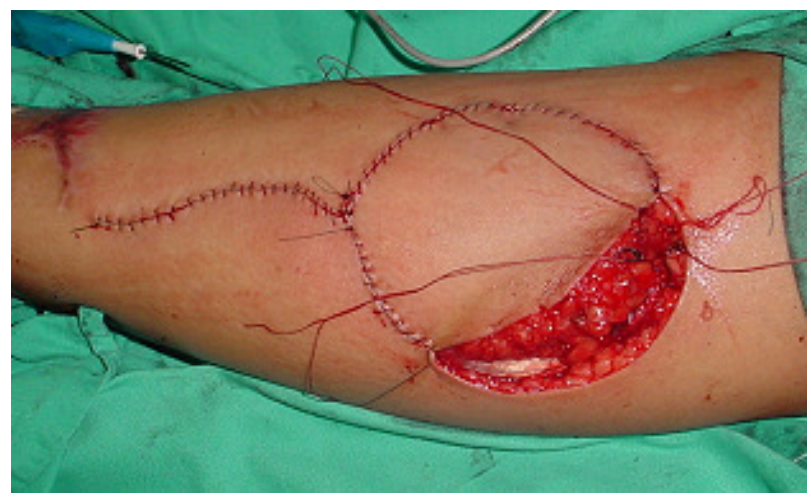

Figura $\mathbf{N}^{\circ}$ 2. Se regresa el colgajo a su lecho y se repara su pedículo. 


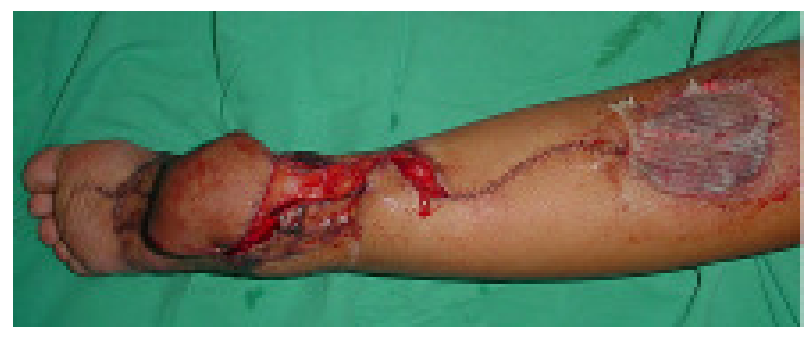

Figura $\mathbf{N}^{\mathbf{0}}$ 3. El colgajo sural después de 02 a 03 semanas se transpone al lecho receptor.

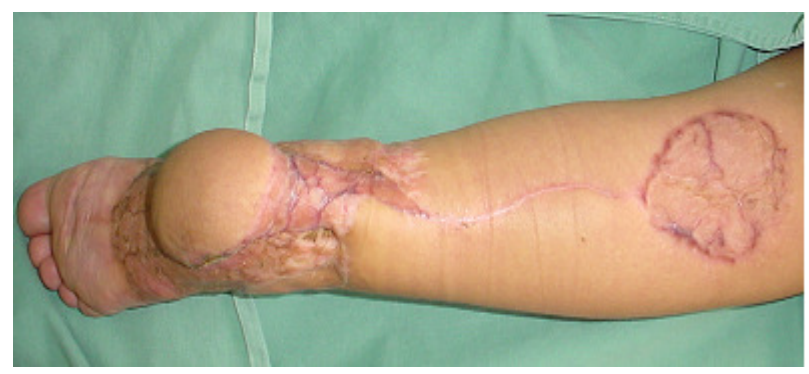

Figura $\mathbf{N}^{\circ}$ 4. Seguimiento del resultado después de 04 meses.

dió de alta al paciente. El control se realizó en forma ambulatoria durante las siguientes cuatro semanas de la cirugía (Figura $\mathrm{N}^{\circ} 4$ ).

Todos los pacientes fueron derivados a continuar su tratamiento en terapia física.

\section{RESULTADOS}

Fueron intervenidos un total de 8 pacientes: 5 hombres y 3 mujeres, cuyas edades oscilaron entre 8 a 65 años de edad, con una media de 37.3 años. La distribución de los grupos etareos se aprecia en la tabla $\mathrm{N}^{\mathrm{o}} 1$.

Las lesiones en su totalidad fueron úlceras crónicas y la causa más frecuente fue de origen traumático $(75 \%)$

Tabla N 1. Distribución por grupo etáreo.

\begin{tabular}{cc}
\hline Grupos etáreos & Número de pacientes \\
\hline 0 a 20 años & 02 \\
20 a 40 años & 02 \\
40 a 60 años & 03 \\
> a 60 años & 01 \\
TOTAL & $\mathbf{0 8}$ \\
\hline
\end{tabular}

(Tabla No2).

Las zonas afectadas y que recibieron cobertura con colgajo fueron: tercio distal de pierna (37.5\%), maléolos $(12.5 \%)$ y talón, esta última zona fue la más frecuente $(50 \%)$. Todas las lesiones comprometían la zona del pedículo vascular del colgajo sural.

El tiempo que estuvo el colgajo sural en su etapa de retardo fue en promedio de 3.4 semanas. Las complicaciones en esta etapa fueron mínimas, representadas por dolor posquirúrgico leve y sólo un paciente presentó signos de flogosis, que se trató con antibioticoterapia y curaciones. No se presentó ninguna manifestación de compromiso vascular del colgajo en esta etapa.

El procedimiento de la segunda etapa quirúrgica se realizó sin ningún inconveniente. La zona donante se cubrió con injerto de piel parcial. Todos los colgajos tuvieron la zona de su pedículo libre, es decir, no se realizó tunelización para transportar el colgajo al lecho receptor.

El colgajo estuvo viable en el $100 \%$ de los defectos cubiertos. La complicación más frecuente fue congestión venosa, (2 pacientes) seguida por necrosis

Tabla N². Causas de lesión.

\begin{tabular}{cc}
\hline Causa de lesión & Número de pacientes \\
\hline Trauma & 06 \\
Osteomielitis & 01 \\
Pie diabético & 01 \\
TOTAL & $\mathbf{0 8}$ \\
\hline
\end{tabular}

Tabla $\mathbf{N}^{\mathbf{0}}$ 3. Complicaciones.

\begin{tabular}{c|c}
\hline Complicaciones & $\begin{array}{c}\text { Número de } \\
\text { pacientes }\end{array}$ \\
\hline Ninguna & 03 \\
Congestión venosa & 02 \\
Necrosis parcial & 01 \\
Congestión venosa + necrosis & 02 \\
parcial & \\
TOTAL & $\mathbf{0 8}$ \\
\hline
\end{tabular}


parcial (Tabla №3), identificada como epidermolísis que comprometió el borde distal del colgajo en un paciente.

En el seguimiento entre 2 meses a 1 año, se encontró que el colgajo sural ofreció una cubierta funcional adecuada.

\section{DISCUSIÓN}

Las lesiones de extremidades inferiores que comprometen el tercio inferior de piernas, talón y maléolos siempre han constituido un reto para el cirujano plástico, debido que compromete zonas que presentan escaso tejido adyacente para realizar colgajos locales comprometiendo en la mayoría de casos sus pedículos, que dificultan y limitan su uso $(2,3)$.

La microcirugía se ha convertido en una alternativa para reconstruir los defectos en extremidades, sin embargo este procedimiento requiere una implementación adecuada y personal debidamente entrenado, lo que no esta siempre al alcance de todos los cirujanos, ni en las instituciones de salud. Asimismo es importante agotar los recursos mas sencillos y que pueden estar al alcance de la mayoría de cirujanos y de las instituciones.

El colgajo sural es técnicamente fácil de realizar y cuya característica fasciocutánea ofrece una excelente cobertura, sobretodo para dar un soporte de tejidos blandos en las zonas de apoyo, como en los talones (1, $2,3)$. Uno de sus inconvenientes es la deformidad estética de la zona donante, en los primeros meses, que luego mejora con el tiempo.

Una de las contraindicaciones descritas para la realización del colgajo sural es que la lesión o secuela comprometan la zona de su pedículo vascular. La técnica diferida o de retardo es un recurso técnico para permitir que los colgajos presenten una mejor viabilidad en condiciones adversas de aporte vascular. Durante esta etapa el colgajo depende únicamente del aporte sanguíneo del pedículo vascular que al inicio es insuficiente y que mejora progresivamente.
Nosotros hemos tenido cuidado de evaluar los efectos favorables y desfavorables para aplicar la técnica diferida en el colgajo sural en los pacientes motivo del estudio. Este método nos ha permitido seguir contando con el colgajo sural como alternativa de reconstrucción en extremidades inferiores cuando las condiciones de las zonas donantes sobre todo del pedículo vascular están dañadas.

En conclusión, la técnica de colgajo sural diferido es útil en la reconstrucción de extremidades inferiores, en los cuales la lesión compromete su pedículo vascular, mejorando su viabilidad.

\section{Correspondencia:}

Victor Huiman Lazo

Dirección: Jr. Libertad 1474 Dpto 303-A

Magdalena del Mar Lima Perú

Teléfono: 511-97356276

e-mail: victorhuiman@viabcp.com

\section{REFERENCIAS BIBLIOGRÁFICAS}

1. Le Fourn B, Caye N, Pannier M, M.D. Distally Based Sural Fasciomuscular Flap: Anatomic Study and Application for Filling Leg or Foot Defects Plastic and Reconstructive Surgery 2001;107:67-72 .

2. Seng-Feng Jeng, Ching-Hua Hsieh, Yur-Ren Kuo, Tsan-Shiun Lin, Fu-Chan Wei. Distally Based Sural Island Flap.Plastic and Reconstructive. Surgery 2003; 111(2): 840-841.

3. Figueiredo Almeida M, Roberto da Costa P, Yukio R. Reverse-Flow Island Sural Flap.Plastic and Reconstructive. Surgery 2002;109:583-591

4. Hollier L, Sharma S, Babigumira E, Klebuc M. Versatility of the Sural Fasciocutaneous Flap in the Coverage of Lower Extremity Wounds. Plastic and Reconstructive Surgery 2002; 110(7): 1673-1679.

5. Baumeister S, Spierer R, Erdmann D, Sweis R, Scott L, Germann G. A Realistic Complication Analysis of 70 Sural Artery Flaps in a Multimorbid Patient Group. Plastic and Reconstructive Surgery 2003;112(1): 129-140.

6. Cavadas P. Reversed Saphenous Neurocutaneous Island Flap: Clinical Experience and Evolution to the Posterior Tibial Perforator-Saphenous Subcutaneous Flap. Plastic and Reconstructive Surgery 2003; 111(2): 837-839.

Recibido: 26/01/04

Aceptado para publicación: 25/06/04 